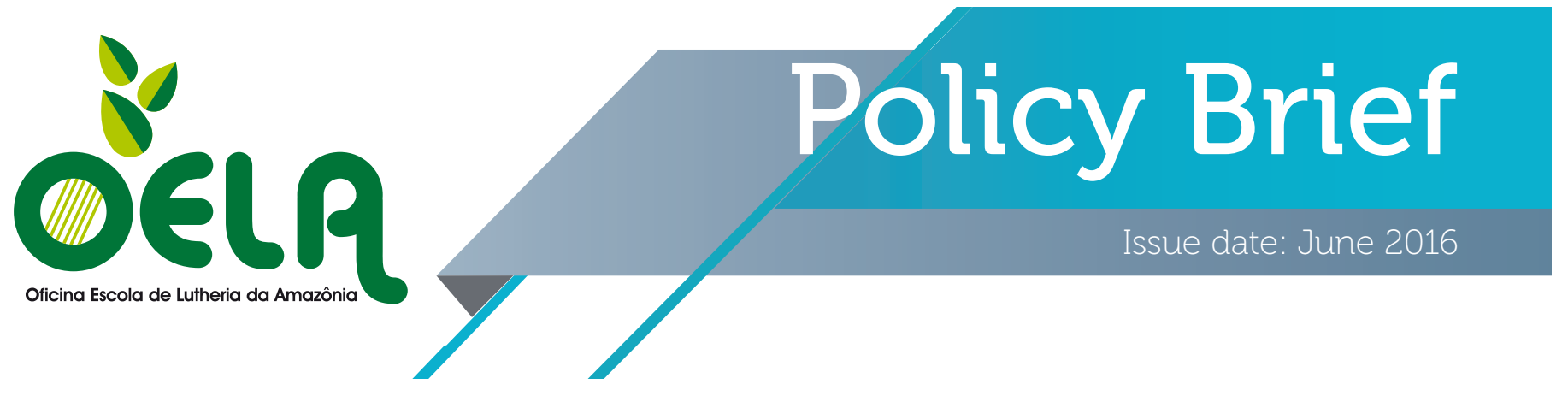

\title{
The Brazilian experience with community protocols and the building of prior informed consent to protect traditional knowledge
}

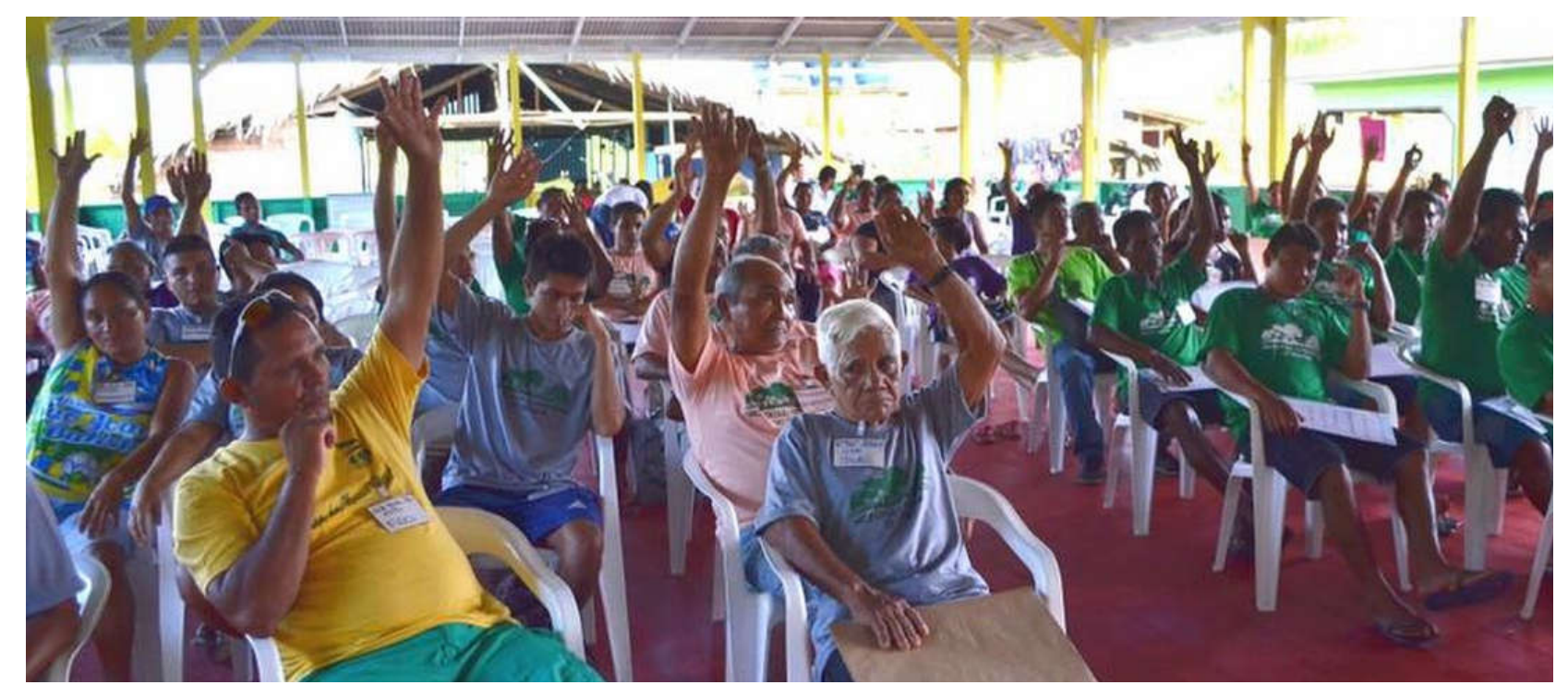

Prior informed consent is a growing concern today for indigenous peoples and traditional communities in Brazil. The land they occupy, which is about $25 \%$ of the national territory, is among the best conserved in the country and there are approximately $4,5^{1}$ million people that depend on this land for their livelihood. These communities have very diverse social and historical backgrounds and their traditional knowledge of biodiversity is of significant value for the economic purposes of several technology based sectors. Within this context, community protocols became of special interest as they support the delineation of customary law to regulate interaction between communities and external stakeholders. One experience of a community protocol which is emblematic for its innovation and scope is being developed in the Bailique Archipelago community, at the mouth of the Amazon river, and is becoming a model to be adopted by communities in other regions of the country.

The use of genetic compounds from Brazilian biodiversity is in the eve of seeing a boom. Following 14 years of constraints in research due to restrictive national regulation, access to biodiversity and associated traditional knowledge will become simpler due to a 
recently adopted bill on Access and Benefit Sharing (ABS), which was passed in May 2015. More friendly to business and resear$\mathrm{ch}$, it is expected that the pace of product development based on Brazilian biodiversity will increase drastically with this new legislation. At the same time, associated traditional knowledge held by local communities is in the spotlight. Consequently, these communities are concerned about their technical capacity to elaborate favorable prior informed consent terms on complex themes such as ABS. Hence community protocols are increasingly being pointed out as instruments of choice by such traditional communities to ensure consent is properly achieved. The benefits of adopting community protocols in the Amazon context seem to be broad.

\section{BRAZILIAN SCENARIO ON ABS}

Brazil is the most biodiverse country in the world, hosting around $15 \%$ of all living species, most of them from the Amazon bioma ${ }^{2}$. As such it plays a central role in the world conservation agenda and domestic dispositions on that matter are generally followed with interest. On the subject of genetic resources, national legal framework derives from the implementation of the 3rd objective of the Convention on Biological Diversity (CBD) that affirms the right of the provider country to receive benefits as a counterpart for the use of their biodiversity. The logic behind it is that efforts for conservation should be compensated by parties with a more consolidated bio-tech users sectors.
Local and traditional communities are directly affected by this legal framework since they hold ancestral knowledge on the uses of biodiversity ${ }^{3}$. Industrial sectors may strongly profit from such traditional knowledge as this knowledge is a shortcut in the development of new products. Therefore, Access and Benefit Sharing (ABS) as a market scheme devoted for conservation of biodiversity incorporates provisions to protect communities' rights, trying to ensure fair negotiations between them and other stakeholders.

In the prevailing scenario, communities barely collected benefits arising from the commercial use of their associated traditional knowledge. The figures involving mutually agreed terms on record are unsatisfactory ${ }^{4}$. Between 2002 and 2014, only 68 contracts concerning the use of traditional knowledge were registered by the Brazilian Genetic Management Council. In addition, several contracts did not share any benefits since no commercial product was generated and those that attained that goal allocated an average of $0.05 \%$ of net revenues from the product sales.

Legal and institutional arrangements are to change with the new bill on ABS. Nevertheless, prior informed consent is still to be granted by a holder of traditional knowledge to a user stakeholder in accordance with private law regulations. As a result, tackling capacity gaps between parties to negotiate fair terms become a central issue. 


\section{ÖGLA \\ CUSTOMARY LAW AND COMMUNITY PROTOCOLS}

Human rights advocacy groups support the perspective that customary local rules and regulations constitute one of the major assets of traditional communities. These rules are invariably in operation in almost all traditional communities and are the basis for their internal governance. In this sense, the dispossession of territories and environmental assets go hand-in-hand with the loss of local consuetudinary law ${ }^{5}$. Therefore, they need to be organized in order to strengthen capabilities and reinforce local institutions.

One way to achieve that is through a community protocol that constitutes the systematization of operating customary law in a given community. More specifically, the objective of building a community protocol is to empower people and traditional communities with the expectation that they will feel prepared to engage in a dialogue and negotiations with any external agent on equal terms, strengthening the community's understanding of their own rights and establishing the importance of conservation and sustainable use of biodiversity.

In this sense, the development of a community protocol is not necessarily a response to an outside threat but it becomes an instrument of community empowerment, management and control of their territory and natural resources ${ }^{6}$. Community protocols prepare communities to be proactive rather than only reactive to outside challenges.

\section{The BaILIQUe COMMUNITY PROTOCOL PROJECT}

For the past two years, the Amazon Working Group (GTA) ${ }^{7}$ has been working on a project to construct the first community protocol of its kind in Brazil. The aim is to have communities with a protocol that answers to their needs but also a community that is well organized and structured in order to negotiate with external actors.

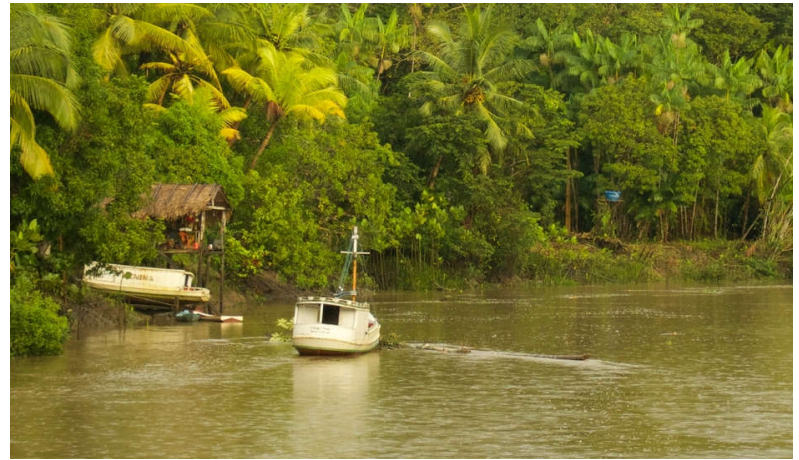

This project is being developed at the Bailique archipelago, which is approximately 200 $\mathrm{km}$ from the city of Macapá in the state of Amapá, Brazil, being located at the mouth of the Amazon river reachable only via boat. The archipelago is composed of eight islands and fifty-one official communities with ten thousand inhabitants according to the Community Council of Bailique. The area is composed in large parts of wetlands, therefore streets and houses are built on stilts.

Communities are mainly composed of fishermen and extractivists, although in some 
communities it is possible to find small animal farms (pigs, cattle, chicken and buffalos), small scale agriculture, woodworker and naval builders. Despite this variety of activities, their main income comes mostly from fishing and sale of açaí berries.

This project has two specific phases convering different coordinated aspects:

- The first phase of the project supports communities in the development of their own community protocol. The methodology developed works with a bottom-up approach where the community is the one to feed in the information, demands, needs and challenges to be present in their protocol.

- The second phase is when, with the protocol in hand, the community starts to organize and improve their production methods, identifying new opportunities in their territory and potential markets to be partners with.

These phases are interconnected, given that phase 2 of the project is essential for strengthening the community protocol developed in the first year.

\section{INITIAL RESULTS}

Following the first twenty-four months of execution of the project, a set of results may be observed at the community level, including the acquisition of capabilities on technical topics. Among them, we can list:

1. Basic knowledge of the text of the Convention on Biological Diversity and the Nagoya Protocol

2. Internalization of the main concepts of Access and Benefit Sharing instruments

3. Understanding of the technological development in the bio-tech field and the relevance to the industrial sector of their traditional knowledge

4. Strengthening of their local institutions

5. Interest of adopting a participatory bottom-up approach to engage in talks with external stakeholders

6. Identification of public policies aiming at strengthening their communities and increasing their income

7. Importance of building a dialogue with key official institutions such as public prosecutors, ministries and state offices.

8. A broad view on stocks and natural resource management

9. Awareness of the shortage of natural resources and unsustainable use of species, deforestation, erosion of community river bank 


\section{Lessons Learned and Recommen- DATIONS}

Historically, the use of associated traditional knowledge of local communities has been done without their consent or sharing of benefits. With the new legislation in place and the pressure of the bio-tech sector to access biodiversity and traditional knowledge at a faster pace, it is essential to prepare communities for dialogue with various stakeholders by strengthening their customary laws.

Looking at the Bailique experience in constructing their community protocol, it is possible to identify some areas that need special attention.

\section{(i) Community Participation}

It is essential that the community is involved in all phases of the project, taking ownership of it from the very early start so that when the project finishes they are prepared to use the protocol to improve their rights and resource management systems. They should be able to shape the activities and the content of the discussion in order to truly own the process.

\section{(ii) Prevent competition}

It is not uncommon that a given associated traditional knowledge is shared by several communities. Competition among communities to receive benefits, on a supply and demand scheme, would profit solely the industrial or commercial sectors. Efforts should be made to prevent this scenario from happening. The replication of community protocols in other communities holding the same traditional knowledge would be a major contribution in that sense.

\section{(iii) Natural resources management}

As part of the process to strengthen the capabilities to engage with external actors, the community must identify the potential of their natural resources stocks and improve the quality and sustainability of their production methods. This process should be guided by the community protocol in order to strengthen the internal governance of the community.

\section{Conclusion}

The implementation of the new legislation on access and benefit sharing in Brazil brings to the forefront of the debate the need for traditional communities to secure their right to be active agents in the ABS process. It is, therefore, paramount that the right for free, prior, informed consent is guaranteed and that there is a protection of the customary norms of these societies.

The building of community protocols is one way to achieve this and the Bailique experience shows that the process of constructing a community protocol also brings awareness about sustainable use of natural resources and it contributes to the strengthening of local institutions. Certainly, community protocols can be an important tool to 
empower communities to have an equal dialogue with external stakeholders, ensuring their right to be consulted is guaranteed, their local norms and traditional knowledge is respected, contributing in this way to the maintenance of their livelihood and conservation of local biodiversity.

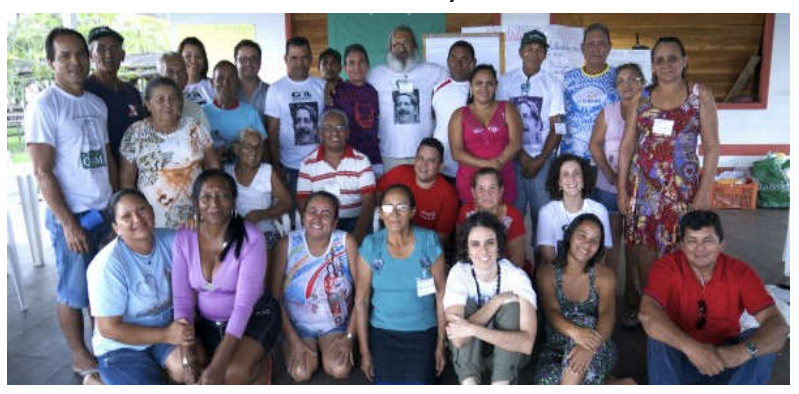

\section{OELA Policy Brief}

Editors: Rubens Gomes and Roberta Peixoto Ramos

Oficina Escola de Lutheria da Amazônia-OELA Rua 22, Quadra O, no 08.

Conjunto São Cristóvão

Bairro: Zumbi II - Manaus, Amazonas, Brazil

Postal Code: 69.084-580

Email: olea@olea.org.br

Contact phones: +55 (92) 3017-6761 / +55

(92) 3638-2667

\section{Authors: Carlos Potiara Castro, Roberta Peixoto Ramos}

Carlos Potiara Castro is professor of the Centre for Advanced Multidisciplinary Studies of the University of Brasilia. Roberta Peixoto Ramos is Senior Project Manager at the Oficina Escola de Lutheria da Amazônia and Ph.D. Candidate in Political Science at the London School of Economics and Political Science.

Keywords: community protocols, prior informed consent, access and benefit sharing, customary law, riverain communities

\section{Endnotes:}

1. Silva Junior, Gladstone (2009). Traditional communities and the struggle for ethnic and collective rights in the south of Brazil. In Revista da Faculdade de Direito da Universidade Federal de Goias. 33(2): 128-142

2. Groombridge, B. and Jenkins, M. D. (2002). World Atlas of Biodiversity. UNEP and University of California Press.

3. Lal, Rhadika and Sorte Junior, Waldemiro (2011). Where biodiversity, traditional knowledge, health and livelyhoods meet: institutional pillars for the productive inclusion of local communities (Brazil case study). in Working paper series. International Policy Center for Inclusive Growth / UNDP, n. 81.

4. Saccaro Junior, Nilo (2013). O uso dos recursos genéticos para o desenvolvimento sustentável brasileiro. in Boletim regional. Institute for Applied Economic Research, n. 7.

5. Tobin, Brendan (2013). Bridging the Nagoya compliance gap: the fundamental role of customary law in protection of indigenous people' resources and knowledge rights. in Law, environment and development journal. 9(2): 144-162

6. Booker, Stephanie et. all. (2014). Community Protocols: A Bottom Up Approach to Community Participation. in 3rd UNITAR - Yale Conference on Environmental Governance and Democracy.

7. The Amazon Working Group (GTA) is a network of more than 600 civil society organizations of traditional communities, indigenous people and traditional farmers. 